\title{
Use of an impervious wound edge protector decreased postoperative wound infection
}

Sookhai S, Redmond HP, Deasy JM. Impervious wound-edge protector to reduce postoperative wound infection: a randomised, controlled trial [Letter]. Lancet 1999 May 8;353:1585.

\section{QUESTION: In patients having abdominal surgery, does the use of an impervious wound edge protector reduce postoperative wound infections?}

\section{Design}

Randomised \{allocation concealed*\}, $\uparrow$ blinded (outcome assessor), * controlled trial with 30 day follow up.

\section{Setting}

Cork, Ireland.

\section{Patients}

352 patients ( $56 \%$ women) who were having transabdominal surgery for gastrointestinal disease. Follow up was complete.

\section{Intervention}

All patients received systemic antibiotic prophylaxis and povidone iodine skin preparation and were allocated either to an impervious wound edge protector $(n=170)$ or to no wound edge protector $(n=182)$. The protector was an impermeable plastic drape attached to the abdomen with adhesive patches. A hole in the middle of the protector ringed by semirigid plastic protected the abdominal wound edge from viscera, viscera contents, contaminated instruments, and gloves.

\section{Main outcome measures}

Postoperative wound infection (presence of purulent discharge, culture positive wound discharge, pain or tenderness, localised swelling, erythema, or cellulitis occurring within $30 \mathrm{~d}$ of surgery). The wounds were categorised for extent of contamination: clean contaminated (minor interruption in aseptic technique or minor spillage from the gastrointestinal tract), contaminated (major interruption in aseptic technique or substantial spillage), and dirty (gross faecal spillage).

\section{Main results}

The use of impervious wound edge protectors decreased the rate of postoperative wound infection $\{\mathrm{p}<0.001\} \ddagger$ (table). Within the 3 contamination groups, wound edge protectors decreased the rate of infection in patients with contaminated wounds $\{\mathrm{p}<0.001\} \neq$ but not in patients with clean contaminated $\{p=0.12\} \ddagger$ or dirty $\{\mathrm{p}=0.15\}$ 末 wounds (table).

\section{Conclusion}

In patients having abdominal surgery, the use of an impervious wound edge protector reduced postoperative wound infections.

*See glossary.

$\dagger$ Information supplied by author.

的 Values calculated from data in article.

\section{COMMENTARY}

Wound infections are an important cause of morbidity after abdominal surgery. Perioperative antibiotic prophylaxis reduces the risk for infection in clean contaminated surgery; other prophylactic strategies are less well defined. The study by Sookhai and colleagues suggests that use of a plastic wound edge protector can further reduce risk for infection. The data are both statistically significant and biologically plausible: the greatest benefit occurs in contaminated wounds, where the bacterial load in previously uninfected subcutaneous tissues is the greatest.

Should we change surgical behaviour? I believe not, although the findings merit further evaluation. Wound infection rates in this series are high. The authors' baseline rate of $13 \%$ in clean contaminated wounds is substantially above the $3.3 \%$ rate reported by the US National Nosocomial Infection Surveillance System study. ${ }^{1}$ Furthermore, previous randomised trials of wound protectors have failed to show a reduction in wound infection rates. ${ }^{2}{ }^{3}$ Finally, the economic benefit postulated by the authors is almost certainly inflated.

An abbreviated report such as this research letter is a tease that leaves the reader intrigued but unconvinced. One wants further details on inclusion and exclusion criteria, the definitions used, the methods of surveillance, the analytic plan, and the outcome data describing the nature and timing of the wound infections that developed. On the basis of this elliptical report, the practice appears reasonable when the probability of contamination is high, for example, when operating in penetrating abdominal trauma or on an obstructed gastrointestinal tract. Wider application should await the result of a more rigorously designed multicentre study.

John C Marshall, MD Toronto General Hospital Toronto, Ontario, Canada

1 Culver DH, Horan TC, Gaynes RP, et al. Am J Med 1991;91:152S-7S

2 Psaila JV, Wheeler MH, Crosby DL. Br J Surg 1977;64:72932.

3 Nystrom PO, Broome A, Hojer H, et al. Dis Colon Rectum $1984 ; 27: 451-3$ 